DOI: https://doi.org/10.11144/Javeriana.upsy16-3.adac

\title{
Acción con daño: del asistencialismo a la construcción social de la víctima. Mirada a procesos de reparación e intervención psicosocial en Colombia
}

\author{
Action with Harm: From Assistance to the Social Construction of \\ the Victim. A View of the Psychosocial Reparation and Intervention \\ Processes in Colombia
}

\author{
Juan David Villa Gómez \\ Universidad de San Buenaventura, Colombia \\ ORCID: http://orcid.org/0000-0002-9715-5281 \\ Daniela Barrera Machado \\ Universidad de San Buenaventura, Colombia \\ Laura Arroyave Pizarro \\ Universidad de San Buenaventura, Colombia \\ Yirley Montoya Betancur \\ Universidad de San Buenaventura, Colombia
}

\begin{abstract}
a Autor de correspondencia. Correo electrónico: juand.villa@usbm.edu.co

Para citar este artículo: Villa Gómez, J. D., Barrera Machado, D., Arroyave Pizarro, L., \& Montoya Betancur, Y. (2017). Acción con daño: del asistencialismo a la construcción social de la víctima. Mirada a procesos de reparación e intervención psicosocial en Colombia. Universitas Psychologica, 16(3), 1-13. https:// doi.org/10.11144/Javeriana.upsy16-3.adac
\end{abstract}

psicosocial en Colombia. Universitas Psychologica, 16(3), xx-xx. https://doi.org/10.11144/Javeriana.upsy 16-3.adac

\section{RESUMEN}

Este artículo, producto de la investigación "Construcción de significados sobre reparación institucional y reparación desde abajo en víctimas del conflicto armado" — desarrollada en la Universidad de San Buenaventura, Medellín-, utilizó el método cualitativo, con enfoque fenomenológicohermenéutico y un muestreo no probabilístico, tipológico e intencional. En el municipio de San Carlos, se realizaron 12 grupos de discusión (SC$\mathrm{GF}$ ), 7 entrevistas individuales (SC-EI) y 5 entrevistas grupales (SCEG). En Medellín se desarrollaron 8 grupos de discusión (AM-GF) y 12 entrevistas individuales (AM-EI). Finalmente, se hicieron 32 entrevistas en profundidad (P-E) a profesionales que manifestaron desgaste intenso en su labor. En todos estos escenarios emergió la categoría "Acción con daño", evidenciando incoherencias, problemas en proyectos de reparación psicosocial y afectaciones que profundizan el daño.

Palabras clave

Acción con daño; reparación institucional; intervención psicosocial; revictimización; identidad de víctima

\begin{abstract}
This article, product of research "Construction of meanings on institutional reparation and reparation from below into victims of armed conflict", it is a process developed from San Buenaventura University, Medellin. The qualitative method was used, with phenomenologicalhermeneutical approach and a non-probabilistic, typological and purposive sampling. In the municipality of San Carlos, 12 groups of discussion were made (SC-GF), 7 individual interviews (SC-EI) and 5 group interviews (SC-EG) were performed. In Medellin we develop
\end{abstract}


8 groups discussion (AM-GF) and 12 individual interviews (AM-EI). Finally we conducted 32 in-depth interviews (PE) to professionals who showed heavy wear in their work. In all these scenarios, it emerged the category "Action with harm", demonstrating inconsistencies, problems in psychosocial reparation projects and effects that deepen the harm.

Keywords

Action with harm; institutional reparation; psychosocial intervention; revictimization; victim identity

\section{Introducción}

La investigación "Construcción de significados sobre reparación institucional y reparación desde abajo en víctimas del conflicto armado" encontró deficiencias graves en procesos de reparación e intervención psicosocial desarrollados por el Estado colombiano en el marco de la Ley 1448 de 2011 (Congreso de la República de Colombia, 2011); estos involucran unas cuantas acciones casi siempre ligadas a la indemnización, además de la exclusión de miles de víctimas y acciones no coordinadas entre diferentes instituciones (Villa \& Insuasty, 2015, 2016b). Junto con lo anterior, identificamos que la participación de las víctimas en la planificación y ejecución de proyectos ha sido meramente formal, para "avalar" decisiones ya tomadas por instancias tecnoburocráticas. De esa manera se afectan las dinámicas de resistencia y organización comunitaria, especialmente en el municipio de San Carlos, presentado por el Estado colombiano como emblemático dentro del proceso de reparación en el país (Villa \& Insuasty, 2016a).

La rehabilitación psicosocial ha representado un fracaso, dadas las fallas en la implementación de programas como el Programa de Atención Psicosocial y Salud Integral a Víctimas (Papsivi), del Ministerio de Salud, y otros desarrollados por la Unidad de Atención y Reparación a Víctimas del Conflicto Armado (UARIV) y otras instancias, que incluyen incoherencias sobre la perspectiva psicosocial, tiempos exiguos para elaborar y transformar experiencias límite, sin lograr reparar el daño padecido (Villa, 2016). La investigación permitió acercarse, además, al desgaste emocional y malestar ético en profesionales que trabajan en estos procesos; también se encontraron rupturas emocionales, desgaste físico y afectivo, crisis éticas y de sentido.

En todos estos escenarios, se evidenciaron claras afectaciones y daño, tanto en comunidades como en profesionales; por tanto, no se está logrando una reparación integral, lo que genera consecuencias negativas, desestructuradoras y revictimizantes. Este texto recoge voces de participantes en la investigación, para dar cuenta de acciones que agudizan el daño o generan nuevas afectaciones, intentando comprender lógicas subyacentes y consecuencias implicadas.

\section{Antecedentes y marco referencial}

El concepto "Do No Harm", traducido al español como "acción sin daño", fue introducido en el marco de la ayuda humanitaria y la cooperación al desarrollo por una ONG norteamericana: Collaborative for Development Action (CDA), que implementó una metodología para valorar la intervención de expertos y cooperantes en contextos culturales, marcos sociales y geografías diversas a las construidas desde paradigmas occidentales. Dicha metodología diferencia entre factores divisores, generadores de ruptura e indicadores del daño, y factores conectores, que evidencian impactos positivos (García, Huertas, Leonhardt, Riedle, \& Serrano, 2006).

El concepto se incorpora en contextos de conflicto armado y guerra, a mediados de los noventa (Duffield, 2004; Rodríguez, 2007), a través de investigaciones que utilizaron la metodología CDA e identificaron problemas serios en intervenciones en contextos de alta complejidad (Anderson, 2009; Prendergast, 1996). Se destacan los casos de Sudán, donde la ayuda benefició a un actor armado, incrementándose violaciones de derechos y crímenes de guerra (Duffield, 2004); los Balcanes, donde la cooperación no contrarrestó la limpieza étnica ni propició la reconstrucción del tejido social (Pupavac, 2002, 2004), y Ruanda, donde se ejecutó un genocidio evitable frente al complejo de la ayuda internacional (Rodríguez, 2007). 
Las discusiones generadas confrontaron dos modelos de actuación guiados por principios éticos particulares. Un modelo deontológico maximalista cuya premisa fundamental es "salvar vidas por encima de todo", por razones de "humanidad"; que fue debatido por otro, fundamentado en una lógica consecuencialista y de responsabilidad, donde además de atender la situación de emergencia, se plantean las preguntas: ia quién podría beneficiar la ayuda? ¿Es perjudicial la ayuda? Dando bases a la construcción del enfoque "acción sin daño".

De acuerdo con la investigación nacional e internacional se han identificado algunas de las prácticas que pueden ser fuentes de potencial daño (Tabla 1).

\section{TABLA 1}

Prácticas que pueden generar daño

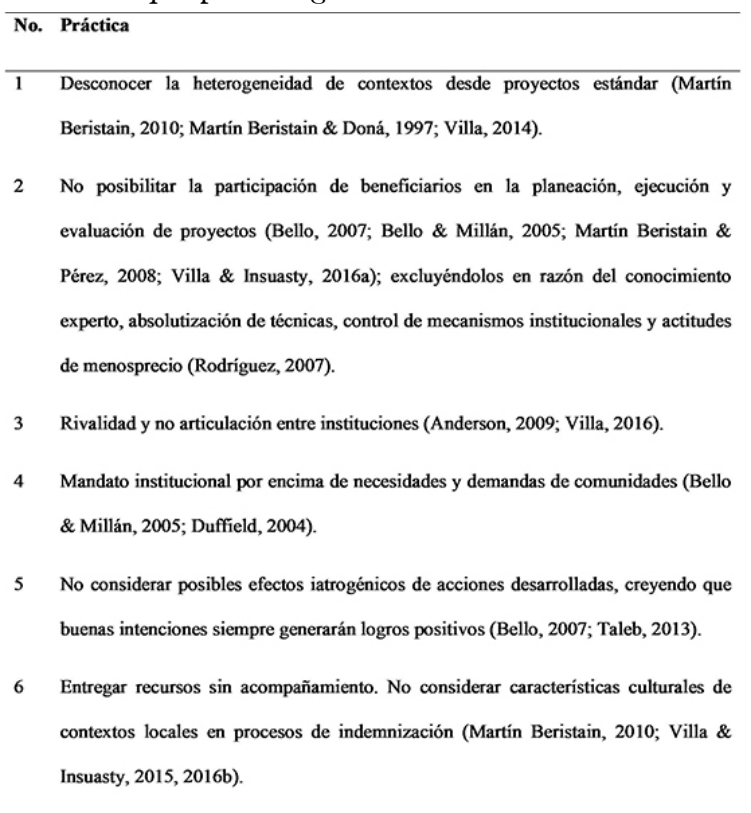

Fuente: elaboración propia.

En Colombia, este enfoque ingresa a la intervención social en el marco de cooperación a organizaciones locales y comunidades afectadas por el conflicto armado. El Consorcio de Cooperación Suiza en Colombia (Cosude) introduce el tema entre 2003 y 2004 (Rodríguez, 2007); posteriormente, agencias de Naciones Unidas lo promueven entre ONG, relacionándolo con el enfoque psicosocial de la ayuda y la cooperación (Martín Beristain \&
Donà, 1997; Martín Beristain \& Pérez, 2008). En efecto, es acogido y desarrollado con mayor profundidad por investigadores psicosociales, que cuestionan que las intervenciones psicológicas y médicas occidentales no alcanzan a comprender la complejidad de contextos sociohistóricos y culturales donde intervienen; por lo que construyen miradas patologizantes $y$ medicalizadas de la experiencia de los sujetos, sin aportar a la transformación de su situación y profundizando el daño (Arévalo, 2010; Lykes, 2001; Pupavac, 2002, 2004; Summerfield, 2002; Villa, 2013, 2014, 2016).

El Estado también incorporó el lenguaje de este enfoque en programas de reparación y atención a víctimas del conflicto armado, declarando que sus procesos implican un cambio real de la situación de los sujetos y una reparación efectiva. Sin embargo, de acuerdo con la Mesa Psicosocial (2016), estas intervenciones presentan déficits que son potenciales de daño y generan en algunos casos revictimización:

A cinco años de la promulgación de la Ley 1448 de 2011, la respuesta del Estado en atención psicosocial y salud integral, ha sido una serie de "estrategias" y guías desarticuladas de la Unidad de Víctimas y un Programa de Atención Psicosocial y Salud Integral (Papsivi), ineficaz en su alcance e implementación, deficiente en cobertura y calidad del servicio, incapaz de articularse a la exigencia nacional de reconocimiento de daños causados y su consecuente obligación de reparación. (Mesa Psicosocial, 2016) ${ }^{1}$

Desde una mirada estructural, algunos autores sugieren que este problema no obedece solo a metodologías mal aplicadas, sino a la concepción de "desarrollo", puesto que se ha reificado un modelo que configura relaciones sociales, económicas y políticas a la medida de las naciones occidentales. Así, los procesos de intervención que realizan tecnócratas y burócratas en contextos locales se basan en criterios técnicos definidos desde la racionalidad occidental, constituyendo una nueva forma de colonización (De Souza, 2010; Escobar, 2010; 
Montenegro \& Vargas-Monroy, 2015; Rist, 2002).

De acuerdo con diversos investigadores nacionales e internacionales, las intervenciones que generan daño pueden evidenciarse en los siguientes aspectos, como lo menciona la tabla 2:

\section{TABLA 2}

Consecuencias de intervenciones que generan daño No. Consecuencias

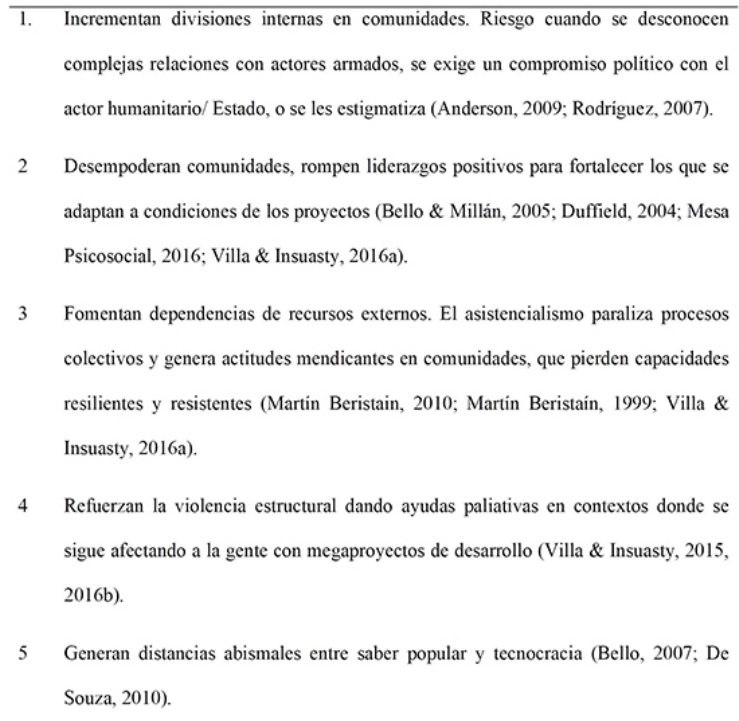

Fuente: elaboración propia.

\section{Método}

Desarrollamos un método cualitativo, recogiendo sentidos y significados en torno al problema planteado, con enfoque fenomenológico-hermenéutico (Sandoval, 1996), focalizando la experiencia vivida. Se realizó un muestreo no probabilístico, tipológico e intencional con triangulación poblacional y en técnicas para recolección de información. En el municipio de San Carlos, se realizaron 12 grupos focales (SC-GF), 7 entrevistas individuales (SC-EI) y 5 entrevistas grupales (SC-EG) con participantes de diferentes sectores sociales (víctimas, líderes comunales, maestros, funcionarios, algunos acompañantes de $\mathrm{ONG}$, organizaciones de mujeres, etc.). En Medellín desarrollamos 8 grupos focales (AMGF) y 12 entrevistas individuales (AM-EI) con víctimas incluidas en el registro único de víctimas. Finalmente, realizamos 32 entrevistas en profundidad (P-E) con profesionales que manifestaron desgaste laboral.

Los relatos resultantes fueron transcritos, realizando análisis del discurso, categorialmente por matrices, procediendo de manera analítica, combinando procesos inductivos y deductivos hasta llegar a interpretaciones que relacionan categorías de análisis, siguiendo estos pasos: un análisis de coherencia (intratextual) donde cada transcripción se analizó independientemente, generando categorías emergentes: "Descontextualización", "clientelismo", "tecnoburocracia”, “operadores", "promesas no cumplidas" y "construcción social de la víctima". A partir de estas, por unidades gramaticales de sentido, se reconfiguró un nuevo texto, aún no codificado.

Posteriormente, se realizó un análisis intertextual por categoría, relacionando contenidos, agrupándolos según sentido y significado para la codificación teórica, en un procedimiento axial (Flick, 2004). Luego se desarrolló la teorización, enlazando la voz de los investigadores, a través de interpretaciones y desarrollos conceptuales, con relatos de participantes y literatura previa sobre el tema, constituyendo un texto que se teje como unidad de sentido.

\section{Resultados}

\section{Descontextualización}

El primer problema detectado es un déficit de lectura del contexto, abordado desde el desconocimiento o solo desde información documental. Esto denota la elaboración de proyectos desde el escritorio, sin comprender contextos locales ni dinámicas del conflicto y representa un verdadero problema para las comunidades. $\mathrm{Si}$ los profesionales no hacen un proceso de inmersión en el territorio, sus actuaciones serán inoportunas, acudiendo a técnicas, herramientas conceptuales y metodológicas 
academicistas. Los proyectos pueden estar bien fundamentados, con especificaciones técnicas claras, pero profundamente descontextualizados, siendo inoperantes o causantes de daño.

En este programa particular, fuimos a trabajar con una población de la que no conocíamos su contexto. Para trabajar bien, es necesario contextualizarse... Y no buscar la información desde Google... (P-E1, 2014). Llegan profesionales de afuera, hacen su taller, su encuentro, lo que tienen que hacer y se van... (SC-GF11, 2014). No es posible hacer programas homogéneos desde Bogotá para todo Colombia, porque tenemos una multiplicidad cultural y social, distintas dinámicas y lenguajes... (P-E4, 2014).

En el papel, los programas estatales dicen haber incorporado los enfoques diferencial, psicosocial y "acción sin daño"; pero en la ejecución prima la tecnoburocracia y la consecución de metas. Por esta razón, se limitan a cumplir requerimientos técnicos institucionales, y así sus acciones no tienen efectos transformadores, pudiendo ser iatrogénicos:

...como está planeado el proyecto es imposible, no está contextualizado, no se pensó teniendo en cuenta las particularidades de todos los municipios, del país, es muy incoherente, con muchos baches, donde prima cifra sobre intervención, es muy horrible, muy desgastante. (P-E2, 2014)

El problema reside en que, desde contenidos universalizantes, homogenizados y estandarizados, no pertinentes para leer un contexto particular, es supremamente difícil desarrollar una acción transformadora en un territorio (Montenegro \& Vargas-Monroy, 2015). Desde la perspectiva psicosocial y de "acción sin daño", los procesos se tejen desde la praxis y la inserción en la vida comunitaria, respetando sus tiempos y momentos (Blanco \& Varela, 2008; Martín Beristaín, 1999).

Sin embargo, desde teorías con pretensiones universalizantes, aplicadas en los territorios, se corre el riesgo de generar intervenciones desenfocadas, ahondando la desestructuración del tejido social y afectando capacidades locales de acción y resistencia (Villa \& Insuasty, 2016a).
Los profesionales-expertos se ponen en un lugar de superioridad, gracias a su descontextualización y atrincheramiento en el saber técnico escindido del saber popular, desconociendo prácticas y saberes de la gente (Villa, 2013). De acuerdo con De Souza (2010), cuando las comunidades no son escuchadas ni su saber es incluido, se da una colonización de su experiencia, obedeciendo a marcos conceptuales como bastión de seguridad, pero ignorando su realidad:

Estos programas vienen de arriba y se manejan desde el escritorio... siempre llegan así y no mueven un dedo para la gente. Quedamos a medias... Lo más grave es que nosotros como comunidad no importamos. Por lo regular llegan a la carrera... Preguntan: "iEstán de acuerdo en que les demos esto?" Y no: "iQué necesitamos?" (SC-GF6, 2014)

Desde este lugar de poder, al "técnico" le cuesta atribuir saber y capacidad a la comunidad, por ello se relaciona con esta desde una lógica de diferenciación y subalternización (Galaz \& Montenegro, 2015), llamando al sujeto "beneficiario" o "usuario". Sin embargo, el efecto paradójico es que la gente aprende: se hace usuaria de los servicios... los "usa": tiende la mano, se "beneficia"; ubicándose en un lugar subalterno, pierde dignidad y poder, acepta su condición de "víctima", esperando mendicantemente que quienes "sí pueden" le ayuden a solucionar su problema.

De otro lado, la gente no legitima el saber técnico: en ocasiones ven a los ejecutores como jóvenes, carentes de experiencia y sin capacidad de leer realidades ni contribuir a transformarlas, por lo que se instaura una relación utilitaria: se espera recibir algún beneficio, pero no se trasciende a otras posibilidades. Desde un punto de vista sistémico, se configura un marco relacional que deja a la gente en este lugar pasivo, esperando intervenciones externas, paralizándose y limitando sus procesos de afirmación y resistencia (Villa \& Insuasty, 2016a).

Finalmente, algunos profesionales se encuentran con una limitación fundamental para ejercicios de reparación: hay escenarios donde no 
Juan David Villa Gómez, Daniela Barrera Machado, Laura Arroyave Pizarro, Et al.

existen condiciones. ¿Cómo puede desarrollarse un proceso de reparación en municipios o regiones que siguen siendo controladas por grupos armados y el conflicto armado sigue cobrando víctimas? ¿Cuáles son los riesgos de estas acciones y a quién pueden terminar beneficiando? Para los profesionales participantes esto entorpece la labor y cuestiona el sentido de la acción, porque no es posible reparar en contextos donde el riesgo permanece y no existen garantías de no repetición:

...hay una dificultad de llevar procesos de atención psicosocial cuando el conflicto en Colombia está vivo... pongo un caso: hace dos días ocurrió una masacre en el barrio donde yo intervenía: uno de los muchachos asesinados es hijo de un señor que yo atendía... uno está haciendo un trabajo para la gente superar los efectos de la violencia, pero todavía está ahí; eso es complejo de abordar; uno quiere trabajar el miedo, pero en realidad este está en el contexto, donde todavía hay violencia, una tensa calma... son cosas reales. (P-E25, 2016)

\section{Clientelismo}

Históricamente se ha configurado en Colombia una ausencia de Estado en los territorios, lo que dificulta la relación con sus instituciones cuando pretenden acceder a las comunidades. Del Estado nacional solo se ve la cara militar y en el Estado municipal las prácticas están mediadas por redes clientelares alrededor de caciques regionales que lo convierten en botín personal. Así, la gente, en lo local, no demanda sus derechos y no establece una relación de ciudadanía (González, Bolívar, \& Vásquez, 2002; Villa, 2014). En medio de este desencuentro y vacío entre la Nación y el municipio, aparecen los programas de reparación con dispositivos técnicos nacionales, con profesionales no contextualizados y sin lecturas de este marco institucional, lo que configura escenarios para una intervención inocua o con daño.

Se añaden a lo anterior las formas de contratación para estos proyectos, que, en muchos casos, obedecen a un "pago de favores políticos”, sin garantizar las competencias necesarias para desarrollarlos. Esta práctica clientelista es habitual y se ha instaurado como normal en relaciones políticas para la gobernabilidad de territorios y la nación (González et al., 2002). Sin embargo, cuando se trata de proyectos que tienen que ver con el dolor humano, la violación de derechos y la pérdida de dignidad, por lo menos, se debería pensar en vincular personas con competencias humanas, vocacionales y profesionales. De lo contrario, terminan ejecutados por incompetentes, que no generan vínculo empático con la comunidad, maltratándola y revictimizándola:

...me sorprendió mucho cuando tuve reuniones con profesionales del programa Papsivi, y me imaginaba que eran muy comprometidos... Son un montón que encontraron empleo aquí, pero lo suyo no es lo psicosocial, les tiene sin cuidado... (P-E31, 2016)

Funcionarios públicos, que no tienen perfil ni capacidades para atender víctimas, están ahí por favores políticos, dicen: "ah ya viene el desplazado otra vez a pedir plata”. (P-E21, 2016)

Burocracia y clientelismo, funcionarios que solo se interesan por su salario, cumplir mínimos requeridos, por evidencias, llenar formatos y alcanzar metas, dejando de lado su función fundamental: acompañar sujetos desde una perspectiva de reparación transformadora. Los participantes reportan malos tratos, desvíos de información, atención precaria y, generalmente, respuestas deficientes a demandas y preguntas. No hay apropiación de procesos, no se desarrollan escenarios de empatía, respeto y acogida, sino que se naturaliza la distancia social y los malos tratos. Los escenarios de intervención se convierten en un contrasentido y una contradicción:

Se aprovechan de nuestra situación, son funcionarios que vienen de otras partes, no saben lo que aquí pasa y solo buscan ganar plata, nos dejan con las manos vacías, con problemas en esos proyectos, porque no funcionan. (SCGF2, 2014)

De hecho, en muchas ocasiones este tipo de funcionarios permanecen por tiempo prolongado en estos programas, por sus relaciones políticas. De otro lado, para los profesionales participantes 
hay un fuerte dilema ético: algunos deben asumir proyectos que hacen daño, por la necesidad de empleo, en un contexto donde buena parte de la oferta laboral procede de este tipo de instituciones; muchos son conscientes de estar contribuyendo a acciones con daño, a proyectos inocuos que refuerzan el asistencialismo y la desestructuración de las comunidades:

No quisiera volver a trabajar bajo estas condiciones, es un círculo vicioso: soy profesional, estoy desempleada y me llaman para hacer este tipo de atrocidades... como no tengo plata, necesito trabajar, toca aceptar; pero al terminar quedo reventada, sin ganas. (P-E4, 2014)

\section{Promesas no cumplidas}

Con lo anterior, el abismo entre lo declarado en papel, difundido mediáticamente y la realidad de la ejecución parece infranqueable. En primer lugar, se crean expectativas que luego no se satisfacen: anuncios, publicidad, promesas; pero las acciones no son suficientes como reparación integral. Por eso, la gente termina sintiendo que estos proyectos parecen maquillaje o engaño. No responden a la problemática que están viviendo y, en definitiva, están mal ejecutados. No se realiza un ejercicio de apoyo ni reparación, sino que se genera más desconfianza en las instituciones del Estado; aumenta la rabia, la indignación y la frustración frente a sus políticas públicas, y se confirma la idea de abandono estatal. La gente queda desesperanzada $y$, en interminable espera, posponen sus proyectos de vida, son atrapados en una red institucional que no cumple la promesa de reparar y restituir derechos. Por tanto, quedan insertos en dispositivos de dependencia y desempoderamiento vital (Villa \& Insuasty, 2016a).

El Estado envía muchos funcionarios a informar sobre nuestros derechos, nos llenamos de expectativas, pero no nos dan caminos... Es un maquillaje... hablan de atención psicosocial, enfoque diferencial, pero en realidad el impacto en la comunidad es mínimo. (SC-GF1, 2014)
No tiene sentido esperarle dos o tres pesos al gobierno... estoy asqueada, solo son limosnas... entre más chapaleemos, más juegan con nosotros, no tenemos confianza, ni ganas de esperar, porque nada va a llegar... (AM-GF4; 2015)

Esto obligaría a una posición y acción más responsable por parte del Estado; a clarificar sus límites y abandonar discursos como el que desarrolló la UARIV en 2014, basado en una investigación de la Universidad de Harvard, afirmando que Colombia tiene la mejor política de reparación en el mundo (Villa \& Insuasty, 2015), cuando en realidad la ejecución de dicha política dista abismalmente en la práctica. De otro lado, algunos profesionales participantes expresan que es precisamente esta situación de incongruencia entre lo prometido y lo ejecutado lo que les genera malestar emocional y ético: rabia, impotencia y dolor, porque no pueden responder demandas de la población, cuestionándose el sentido vital de su acción, al ver que su trabajo es ineficaz; que, como idiotas útiles, no logran cumplir el propósito de reparación:

El trauma mío es generar expectativas que no se cumplirán, vender proyectos que no son ni la mitad de lo prometido... sinceramente me da pena, porque llegamos a vender pajaritos, cuentos que no van a pasar, a generar cosas que ni estaban esperando. Proyectos que no cambian nada... Si no mejoran la calidad de vida de la gente ¿Para qué? (P-E19, 2015)

Siento rabia, impotencia, tristeza, desesperanza: llega a ser un asunto tan extremo que ya es resignación... Mucho de lo que me movía, ya no me mueve ahora. (P-E16, 2015)

En este contexto, otro problema grave es la denominada "tramitomanía" y el "paseo institucional", que genera una sensación mendicante, puesto que obliga a la gente a llenar numerosos formatos, buscar papeles, ir y volver a diversas instituciones para lograr algún reconocimiento. Dado que oferta institucional y atención están divididas en varias dependencias, las personas deben repetir su historia y dar cuenta de su situación subjetiva, económica $\mathrm{y}$ emocional varias veces, $\mathrm{y}$ esto genera 
procesos revictimizantes. De hecho, en muchas ocasiones deben acudir a mecanismos legales de protección de derechos: tutelas, derechos de petición, tramitadores o abogados para lograr ser atendidos:

La tramitomanía nos ha llevado al borde del desespero, el cambio permanente de operadores y programas nos pone en unos trámites cotidianos de fotocopias, permisos... (SC-GF1, 2014).

Me están haciendo más daño, porque nosotros yendo a la UAO... en vez de comprarnos una libra de panela o de arroz, vamos y gastamos en pasajes para ver si ya vino el dinero; mandan sacar $\$ 3000$ y $\$ 4000$ en fotocopias, llévelo a la Alpujarra y voltee de un lado para otro; entonces, en vez de darnos, nos están sacando. (AM-E4, 2014)

\section{Operadores y tercerización}

El problema se agudiza cuando el Estado intenta delegar su acción en organizaciones no gubernamentales (fundaciones, corporaciones, etc.) para aminorar demoras en trámites y agilizar la ejecución. Sin embargo, muchos operadores no siempre cumplen con la experticia práxica y profesional, limitándose a ejecutar actividades descontextualizadas, sin vincular a la gente ni desarrollar procesos. Sencillamente siguen términos de referencia y cumplen un contrato, buscando "utilidad" (Bello \& Millán, 2005). Esto sin mencionar una práctica que parece hacerse común: se contratan entidades que tienen vínculos con políticos o aquellas que ofrecen presupuestos más bajos en licitaciones, sin que sean las más competentes; o quienes no cuestionan ciertas prácticas institucionales y de poder del Estado. Con lo cual quedan excluidas organizaciones que poseen mayor experiencia y una posición crítica (Mesa Psicosocial, 2016).

...la tercerización: ahora el tema de paz y víctimas es un negocio; ahí hay corrupción, plusvalía, llevada al tema humanitario. Me hago rico a costa del trabajo de otro, lo exploto... tener una persona alcanzando metas: un operador "M", la súper ONG, los súper humanitarios, enriqueciéndose y haciendo "patria" a través de otros, pagando mal; eso me parece, éticamente, una cosa complicada, no es correcto... Se está utilizando esa dinámica capitalista en la institución humanitaria, deshumanizando las relaciones. (PE32, 2016)

Así pues, en la práctica, los problemas se mantienen: diagnósticos que se repiten con iguales preguntas, proyectos que quedan a mitad de camino, con riesgo de perderse por tiempos de ejecución limitados, diversas entidades y profesionales que no logran continuidad para garantizar acciones transformadoras, y todo esto genera desconfianza y sospechas. Adicionalmente, la gente siente que pierde recursos en la intermediación del operador, cerrándose la posibilidad para ser incluidos. Una dinámica que implica bajos presupuestos, escasos recursos asignados y un universo de víctimas de gran magnitud, deja de ser solución para convertirse en parte del problema. Finalmente, la saturación de proyectos y acciones inocuas, sumada a la hiperburocratización, termina por limitar posibilidades de reparación, y causa más daño que el que pretende reparar. Adicionalmente, se multiplican "ejércitos" de profesionales sin claridad, descritos de forma coloquial por las comunidades como una "feria de chalecos":

Ahora está "F" antes estuvo "C", antes estuvo otro. Es cosa de locos con los operadores: nos mandan a hacer fichas técnicas de las familias, entonces yo el año pasado estuve con "C", las hice; y este año, entra " $F$ " y mandan la misma ficha... vuelva y pregúntele a la familia lo mismo. ¿Esto qué? Es como si lo que uno hace se perdiera, ellos nunca revisan... (SC-EG3, 2014)

Para la indemnización van a dar un proyecto productivo de 8 millones de pesos, entonces montan el operador y cuando llegan, al cliente ya no le dan sino $\$ 2.5$ millones: insumos, operadores, se comen la plata... un nuevo sistema para atender, un ejército de funcionarios y realmente atención a víctimas... nada. (SCEG1, 2014) 


\section{Razón instrumental y tecnocracia}

¿Por qué sucede todo esto? Como se ha dicho, la planeación se hace desde el escritorio y responde a una lógica financiera, al cálculo de réditos políticos. Por esta razón, la meta, entendida exclusivamente en términos de cifras (número de participantes, número de atenciones, etc.), prima sobre el acompañamiento. De hecho, las acciones se valoran desde costos económicos más que desde procesos transformadores. Un problema de la lógica burocrática: tiempos de contratación, múltiples instancias de revisión, falta de continuidad por vigencias anuales, proyectos ejecutados en solo unos meses, manteniendo iguales metas e indicadores:

...casi todos quienes contratan son economistas, administrativos, no ven la parte humana, solo la económica; y ahí empieza la indignación: me está pidiendo que dé trato con calidad humana a los usuarios, pero me mide por lo económico... tenemos dos lenguajes diferentes: me evalúa a partir de un logro económico, pero me dice que trabaje a partir de conceptos humanos... (P-E29, 2016)

Hay un montón de proyectos que no responden a necesidades de la gente, sino a asuntos políticos, cumplimiento de programas y normas; realmente son sordos y ciegos: atendimos 5000, pero las condiciones de vulnerabilidad son las mismas... (P-E4, 2014)

Quienes trabajan en estos espacios están saturados: desgastados y dañados en su propia persona, en su identidad y dignidad. Experimentan dolor abrumador y desesperanza aprendida, al sentir que se trata de confrontar un sistema más fuerte. Los profesionales pueden perder el sentido y el horizonte, si el proyecto los convierte en "máquinas que no sienten" (P-E5, 2014). Es decir, para ser funcionales, eficientes y eficaces anulan sentimientos empáticos y se acogen a la razón instrumental, desconectándose del sufrimiento del otro. También pueden asumir una posición cínica, donde no importa la persona, sino cumplir tareas, recibir el salario y aferrase al empleo en medio de un mercado laboral complejo: ...sentir que no haces las cosas bien, frustración por responder más a lo administrativo, porque no cumplís con formatos y parámetros; eso me afectó muchísimo, me cansó emocionalmente y se reflejó en mi salud: con gripa, sueño, desgarro por hacer estas cosas (P-E24, 2016)

Me sentí mal, impotente, engañando la gente, utilizándola... Uno termina manoseándola. Estos procesos no pueden ser comparados con una producción en cadena, pero se han reducido a eso: mucha premura por las metas... (P-E5, 2014)

Hay una primacía de la lógica tecnocrática propia de la razón instrumental, que se contrapone a la "razón compasiva" (Blanco \& Gaborit, 2014). Esta última implica una mirada emancipadora que posibilita transformaciones significativas a través de la comunicación participativa y el vínculo solidario, tiempo para la escucha, encuentro y acompañamiento; mientras la razón instrumental rompe, porque es una lógica del objetivo, el informe y la evidencia, no de la transformación ni la relación. Este tipo de mirada, aplicada a procesos humanos, simplifica la acción a una serie tayloriana para cumplir un indicador, un resultado en una cantidad de tiempo.

Sin embargo, las personas y comunidades necesitan más del tiempo previsto en la planeación estratégica, son más que víctimas, son historias de resistencia y dignidad. El problema se produce en tener que cumplir con el proyecto como contrato, sin poder hacer procesos: tiranía del indicador, de lo escrito en papel. Así, se obstaculiza la construcción de confianza, la generación de transformaciones reales en los impactos generados por el conflicto en Colombia, que implica un trabajo de varios años. Así pues, la primacía de metas, indicadores y resultados es potencial de daño.

Las instituciones lo ejecutan en el menor tiempo posible, luego se van, se llevan la información, no hay seguimiento. Toman fotos, evidencian y se van (SC-GF3, 2014).

Después de dos años de estar en el programa, la gente se gradúa y supuestamente superó la extrema pobreza, pero resulta que, al ver la realidad, hay una cantidad de vacíos, de dolores, 
Juan David Villa Gómez, Daniela Barrera Machado, Laura Arroyave Pizarro, Et al.

de ausencias; y resulta que como cumplieron las nueve dimensiones del desarrollo humano, en el papel... ya lo superaron... (P-E22, 2016)

Por esta razón y en contrapunto a esta dinámica, para Martín Beristain $(1999,2010)$ estos procesos se deben hacer desde abajo, con la gente, para la gente, respetando sus ritmos y dinámicas. Esto requerirá mayores esfuerzos de cooperantes y agencias; centrarse más en los procesos comunitarios, que en planear y cumplir objetivos. Es decir, requiere un más allá de la mentalidad tecnocrática que permea toda la acción del Estado.

\section{Discusión: construcción social de la identidad de víctima}

$\mathrm{Al}$ realizar esta mirada investigativa y reflexiva, podemos afirmar que las prácticas que desconocen la heterogeneidad de contextos, promueven el clientelismo, incumplen promesas, fomentan la tramitología, la tercerización y la primacía de la razón instrumental, atrapan a la gente en una lógica que limita sus posibilidades de autonomía, autodeterminación y reconstrucción de proyectos de vida y construyen una identidad social de víctima.

Cuando proyectos de reparación obedecen a lógicas asistencialistas, generan en la gente un lugar mendicante, dependencia y desempoderamiento; hay despilfarro de recursos y una demanda permanente a instituciones y funcionarios, en muchos casos, sin asumir deberes ni responsabilidades. Se va construyendo un lugar de infantilización, que genera, al mismo tiempo, una especie de tiranía de la víctima; puesto que su único lugar es exigir asistencia y "ayudas" paliativas a sus necesidades, mas no sus derechos. Esto no posibilita su transformación subjetiva ni la reconstrucción de su ciudadanía.

Esto responde a una lógica relacional y sistémica, más que a una intención, pues se teje un marco de relación relativamente cómodo para ambas partes: de un lado se privilegia lo asistencial: ayuda económica e indemnización, porque no tiene mayores implicaciones de corresponsabilidad en el acompañamiento y rinde réditos políticos y cuantitativos, siendo una acción visible y medible claramente. Del otro lado, para la gente, solo implica esperar y recibir mediaciones económicas, que traen un acomodamiento pasivo, cuya consecuencia negativa es el desempoderamiento personal y colectivo:

...estamos metidos a un asistencialismo de pobreza y miseria, no vemos ningunos objetivos del Estado en nuestra defensa... las víctimas vamos a quedar peores que mendigos... (SCEG1, 2014)

El Estado fue muy hábil en hacer ver el conflicto de manera asistencial, y le encanta eso: la vaca, la plata, la casa... no más... (SC-GF4, 2014)

Así pues, el peor daño es que las personas se asumen a sí mismas, no como sujetos de derechos, ocupando su condición de ciudadanía, sino como solicitantes de ayuda, a la espera de caridad. Es decir, terminan asumiendo el personaje estereotipado de "víctima", que ha sido social e institucionalmente construido (Guarderas, 2015). Esto implica que parte de la población no asume su propio poder y se pone "a merced" de quienes pueden ayudarle de forma asistencial, alejándose de lo público y del control de la gestión del Estado, que sigue circunscrita a sectores sociales que acaparan el poder. Por otro lado, hay un daño potencial relacionado con la "astucia" para lograr acceder a la asistencia: tramas, falsas declaraciones, tramitadores, etc., que dejan a las personas en un lugar subalterno, sin tomar las riendas de su destino. Así, la reparación integral se convierte en promesa incumplida que des-dignifica, porque no responde a la experiencia de las víctimas, ya que al final no puede pagarse el dolor con dinero.

La construcción de una plantilla narrativa de la identidad de víctima puede tener tres imágenes: la primera, consiste en igualar a la víctima de violencia política con la de una catástrofe natural: "el damnificado". La segunda, es la víctima traumatizada, psicopatologizada, bloqueando el desarrollo de alternativas de intervención psicosocial desde abajo, tendientes a promover resiliencia y resistencia (Villa, 2016; 
Villa \& Insuasty, 2016a). La tercera, es la imagen de la víctima sufriente, lacrimógena, mediática, que vende; cuyos relatos y emociones se vehiculizan para movilizar sentimientos, pero sin generar consciencia. Se construye una identidad desempoderada, que no permite autonomía, ni participación, ni resistencia.

¿Por qué la percepción de la gente de San Carlos sobre sí mismos? ¿Por qué participantes de Medellín asumen un lugar de demanda o queja y no de construcción y transformación? ¿Por qué los profesionales se sienten desgastados y en medio de profundos malestares éticos? Según lo visto en esta investigación, se están haciendo reparaciones e intervenciones psicosociales desde una perspectiva domesticadora, paralizante y victimizante. Vale utilizar la expresión de MartínBaró (1998): "fatalizante", es decir, quitan fuerza a lo que ha significado lo psicosocial como proceso de reconstrucción de tejido social, encasillándolo en acciones técnicas, sin posibilitar transformaciones profundas:

El Estado maquiavélicamente creó los subsidios y todo eso, para que la gente no pensara cómo solucionaba sus problemas... entonces perdemos hasta la condición de reclamar nuestros derechos, nuestros recursos, nos convertimos en ciudadanos pasivos, si es que nos llamamos así, porque ni siquiera el ejercicio mínimo del ciudadano lo ejercemos... (SC-EI1, 2014)

En perspectiva psicosocial, muchas de las acciones de reparación desarrolladas no permiten ver la complejidad de cada contexto, ni la potencialidad que hay en las personas y comunidades, ni su resistencia. Así, los proyectos que ejecutan la Ley 1448 de 2011 terminan siendo una forma de diluir la subjetividad, el empoderamiento del propio proyecto de vida y la capacidad para resistir. Se pierde contacto consigo mismo, con la colectividad y se asume el rol asignado en un escenario de transacción que se refuerza permanentemente: el rol de víctima. Y esto es grave.

\section{Conclusión}

Vemos entonces que es posible evidenciar consecuencias de acción con daño en estos procesos: divisiones internas en las comunidades, riesgo para los profesionales acompañantes, desconocimiento del contexto; desempoderamiento de sujetos y colectivos. Se suma el fomento de la dependencia frente a recursos externos, paralizando colectivos y generando actitudes mendicantes; rupturas de la capacidad resiliente y procesos de resistencia. Se ha reforzado la violencia estructural, en la medida en que no se están transformando condiciones históricas de exclusión y fatalismo, sino que solo se dan ayudas paliativas que generan una distancia abismal entre saber popular y tecnocracia. Adicionalmente, la entrega de recursos sin el debido acompañamiento ha hecho que sean más numerosos los fracasos, que generan daño en familias y comunidades, que los casos exitosos.

Es necesario hacer una diferenciación: en un país como Colombia ha sido fundamental, en términos jurídicos y políticos, que se reconozcan las víctimas y sus derechos. Esto ha sido un logro significativo del movimiento social de derechos humanos. Sin embargo, en términos psicosociales, cuando este estatuto jurídico se confunde con uno identitario, la gente asume el rol asignado, actuando el papel de "damnificada", "traumatizada" o "pobrecita". La asunción de este rol y sus narrativas subyacentes, domestica, subordina y obstruye la lucha social y política de personas y comunidades afectadas por violencia política, e invisibiliza la violencia estructural: opresión histórica, exclusión política y explotación económica de buena parte de la población colombiana.

En síntesis, los procesos de intervención denominados "psicosociales" y las acciones de reparación desarrolladas en el marco de la Ley 1448 terminan siendo contraproducentes. $\mathrm{Si}$ estas acciones empoderaran, transformaran situaciones de opresión, exclusión y violencia, quizás comenzarían a tocar intereses; porque darían poder a la gente, afirmarían su deseo de cambio, lo que pone en aprietos un orden social 
establecido, develando que, quizás, la acción asistencial no es inocente. Desde una visión sistémica y relacional, podría decirse que logra el objetivo: paraliza, bloquea, delimita: Ni más allá de la ayuda, ni menos, donde todo aparenta cambiar para seguir igual.

\section{Agradecimientos}

El proyecto tuvo financiación por la Dirección de investigacions de la Universidad de San Buenaventura - Medellín.

\section{Referencias}

Anderson, M. (2009). Acción sin daño: cómo la ayuda humanitaria puede apoyar la paz o la guerra. Bogotá: Universidad Nacional de Colombia.

Arévalo, L. (2010). Atención y reparación psicosocial en contextos de violencia sociopolítica: una mirada reflexiva. Revista de Estudios Sociales, 36, 29-39.

Bello, M., \& Millán, C. (2005). La intervención institucional en contextos culturalmente distintos: lógicas en tensión y contradicción. Palimpsesto, 5, 250-260.

Blanco, A., \& Gaborit, M. (2014). La razón compasiva y la acción como ideología: una nueva mirada a la Psicología de la liberación. En E. Zubieta (Ed.), Psicología social y psicología política: procesos teóricos y estudios aplicados (pp. 139-170). Buenos Aires: Eudeba.

Blanco, A., \& Varela, S. (2008). Los fundamentos teóricos y axiológicos de la intervención psicosocial. En A. Blanco \& J. Rodríguez (Eds.), Intervención psicosocial (pp. 3-43). Madrid: Pearson, Prentice Hall.

Congreso de la República de Colombia. (2011). Ley 1448 de 2011. Por la cual se dictan medidas de atención, asistencia y reparación integral a las víctimas del conflicto armado interno y se dictan otras disposiciones. Diario Oficial 48096.

De Souza, B. (2010). Descolonizar el saber, reinventar el poder. Montevideo: Trilce.
Duffield, M. (2004). Las nuevas guerras en el mundo global: la convergencia entre desarrollo y seguridad. Madrid: La Catarata.

Escobar, A. (2010). Una minga para el postdesarrollo. Bogotá: Desde Abajo.

Flick, U. (2004). Introducción a la investigación cualitativa. Madrid: Morata y Fundación Paideia.

Galaz, C., \& Montenegro, M. (2015). Gubernamentalidad y relaciones de inclusión/exclusión: los dispositivos de intervención social dirigidos a mujeres inmigradas en España. Universitas Psychological, 14(5), 1667-1680. http:// doi.org/10.11144/Javeriana.up14-5.grie

García, L., Huertas, O., Leonhardt, M., Riedle, P., \& Serrano, J. (2006). Prácticas sensibles a los conflictos y la paz: contribuciones conceptuales y ejemplos de aplicación. Bogotá: GTZ.

González, F., Bolívar, I., \& Vásquez, T. (2002). Violencia política en Colombia. De la nación fragmentada a la construcción del Estado. Bogotá: Cinep.

Guarderas, P. (2015). Tramoyas, personajes y tramas de la actuación psicológica en la violencia de género en Quito. Universitas Psychologica, 14(5), 1569-1582. http:// doi.org/10.11144/ Javeriana.upsy14-5.t pta

Lykes, M. (2001). A critical re-reading of PTSD from a cross-cultural community perspective. En D. Hook, \& G. Eagle (Eds.), Psychopatology and social predjudice (pp. 92-108). Cape Town: UCT Press, JTA.

Martín Beristain, C. (1999). La experiencia de cooperantes y ONG. En C. Martín Beristain, G. Donà, D. Páez, P. Pérez, \& I. Fernández (Eds.), Reconstruir el tejido social (pp. 137-145). Barcelona: Icaria.

Martín Beristain, C. (2010). Diálogos sobre la reparación: qué reparar en los casos de violaciones de derechos humanos. Quito: Ministerio de Justicia y Derechos Humanos.

Martín Beristain, C., \& Donà, G. (1997). Enfoque psicosocial de la ayuda humanitaria. Bilbao: Universidad de Deusto, Instituto de Derechos Humanos.

Martín Beristain, C., \& Pérez, P. (2008). Trauma, development and peacebuilding: A Latin 
American perspective. Belfast: International Conflict Research Institute, International Development Research Center, Unisersity of Ulster.

Martín-Baró, I. (1998). Psicología de la liberación. Madrid: Trotta.

Mesa Psicosocial. (2016). Documento macro de denuncias y recomendaciones: debate de control político del 18 de mayo de 2016. Atención psicosocial en el marco del conflicto armado. Recuperado de http://go o.gl/jytq5g

Montenegro, P., \& Vargas-Monroy, M. (2015). Miradas, formas de hacer y relaciones en la constitución de una investigación crítica. Universitas Psychologica, 14(5), 1833-1852.

Prendergast, J. (1996). Frontline Diplomacy: Humanitarian Aid and Conflict in Africa. Colorado: Lynne Rienner Boulder.

Pupavac, V. (2002). Pathologizing populations and colonizing minds: International psychosocial programes in Kosovo. Alternatives, 27, 448-511.

Pupavac, V. (2004). Psychosocial interventions and the demoralization of humanitarianism. Journal of Biosocial Science, 36, 491-504.

Rist, G. (2002). El desarrollo: historia de una creencia occidental. Madrid: La Catarata.

Rodríguez, A. (2007). El enfoque de la acción sin daño. Bogotá: Programa de Iniciativas Universitarias por la Paz, Universidad Nacional de Colombia. Recuperado de htt p://goo.gl/r8WHPe

Sandoval, C. (1996). Investigación cualitativa. Bogotá: Icfes.

Summerfield, D. (2002). Effects of war: Moral knowledge, revenge, reconciliation, and medicalised concepts of "recovery". British Medical Journal, 325, 1105-1107.

Villa, J. (2013). Horizontalidad, expresión y saberes compartidos: enfoque psicosocial en procesos de acompañamiento a víctimas de violencia política en Colombia. El Ágora USB, 13(2), 289-327. http:// doi.org/10.21500/16578031.91

Villa, J. (2014). Recordar para reconstruir. Medellín: Editorial Bonaventuriana.
Villa, J. (2016). Intervenciones psicosociales en el marco de acciones de reparación a víctimas del conflicto armado colombiano. ECA, 71(744), 81-104.

Villa, J., \& Insuasty, A. (2015). Significados en torno a la reparación, la ayuda humanitaria, la indemnización y la restitución en víctimas del conflicto armado en el municipio de San Carlos. El Ágora USB, 15(2), 419-445. http:// doi.org/10.21500/16578031.162.

Villa, J., \& Insuasty, A. (2016a). Entre la participación y la resistencia: reconstrucción del tejido social desde abajo en el municipio de San Carlos: más allá de la lógica de reparación estatal. El Agora USB, 16(2), 453-478. http:// doi.org/10.21500/16578031.2442

Villa, J., \& Insuasty, A. (2016b). Significados en torno a la reparación, la ayuda humanitaria, la indemnización y la restitución en víctimas del conflicto armado en el municipio de San Carlos (II). El Ágora USB, 16(1), 165-192. http:// doi.org/10.21500/16578031.2171

\section{Notas}

* Artículo de Investigación.

1 La mesa de trabajo estuvo conformada por Corporación AVRE, Tejidos del Viento, Costurero de la Memoria, Colectivo Ansur, Centro de Atención Psicosocial, Corporación Vínculos, Comisión Intereclesial Justicia y $\mathrm{Paz}$, Colectivo Sociojurídico Orlando Fals Borda, Colectivo Psicosocial Colombiano y Corporación Claretiana Norman Pérez Bello. 